\title{
Turboelectric Aircraft Drive Key Performance Parameters and Functional Requirements
}

\author{
Ralph H. Jansen ${ }^{1}$, Dr. Gerald V. Brown ${ }^{2}$ and James L. Felder ${ }^{3}$ \\ NASA Glenn Research Center, Cleveland, Ohio, 44135 \\ and \\ Dr. Kirsten P. Duffy ${ }^{4}$ \\ University of Toledo, Toledo, Ohio, 43606
}

\begin{abstract}
The purpose of this paper is to propose specific power and efficiency as the key performance parameters for a turboelectric aircraft power system and investigate their impact on the overall aircraft. Key functional requirements are identified that impact the power system design. Breguet range equations for a base aircraft and a turboelectric aircraft are found. The benefits and costs that may result from the turboelectric system are enumerated. A break-even analysis is conducted to find the minimum allowable electric drive specific power and efficiency that can preserve the range, initial weight, operating empty weight, and payload weight of the base aircraft.
\end{abstract}

\section{Nomenclature}

$\begin{array}{ll}D & =\text { drag } \\ g & =\text { gravitational constant } \\ h & =\text { fuel energy per unit mass } \\ L & =\text { lift } \\ P_{\text {elec }} & =\text { electrical input power } \\ P_{\text {eleccruise, }}, P_{\text {electakeoff }} & =\text { cruise, takeoff electrical input power } \\ P_{\text {fuel }} & =\text { fuel power } \\ P_{\text {prop }} & =\text { propulsive output power } \\ R_{A C}, R_{E A C} & =\text { range of base aircraft, turboelectric aircraft } \\ S p_{E D} & =\text { specific power of electric drive } \\ T & =\text { total airplane thrust } \\ T_{\text {cruise }}, T_{\text {takeoff }} & =\text { cruise, takeoff thrust } \\ v_{\text {cruise }}, v_{\text {takeoff }} & =\text { cruise, takeoff velocity } \\ W_{\text {elec }} & =\text { electric drive weight } \\ W_{\text {fuel }} & =\text { base aircraft fuel weight } \\ \Delta W_{\text {fuel }} & =\text { weight of extra fuel due to electric drive inefficiency } \\ W_{\text {final }}, W_{\text {finalEAC }} & =\text { final weight of base aircraft, turboelectric aircraft } \\ W_{\text {initial }}, W_{\text {initialEAC }} & =\text { initial cruise weight of base aircraft, turboelectric aircraft } \\ W_{\text {OEW }} & =\text { empty weight of base aircraft (operating empty weight) } \\ W_{\text {pay }} & =\text { payload weight }\end{array}$

\footnotetext{
${ }^{1}$ Electrical Engineer, Electrical Power Systems, Diagnostics and Electromagnetics Branch, 21000 Brookpark Road, Cleveland, Ohio 44135, M.S. 86-11, and AIAA Member.

${ }^{2}$ Physicist, Structural Dynamics, Rotating and Drive Systems Branch, 21000 Brookpark Road, Cleveland, Ohio 44135, M.S. 49-8.

3 Aeronautics System Engineer, Propulsion Systems \& Technologies, Propulsion Systems Analysis Branch, 21000 Brookpark Road, Cleveland, Ohio 44135, M.S. 5-11, and AIAA Senior Member.

${ }^{4}$ Senior Research Associate, Mechanical Engineering Dept., 21000 Brookpark Road, Cleveland, Ohio 44135, M.S. 49-8, and AIAA Member.
} 


$\begin{array}{ll}\alpha & =\text { ratio of takeoff power to initial cruise power } \\ \zeta_{A C}, \zeta_{E A C} & =\text { fuel fraction of base aircraft, turboelectric aircraft } \\ \eta_{\text {elec }} & =\text { electric drive efficiency } \\ \eta_{\text {overall }}, \eta_{\text {overallEAC }} & =\text { overall efficiency of base aircraft, turboelectric aircraft } \\ \eta_{\text {prop }}, \eta_{\text {propEAC }} & =\text { propulsive efficiency of base aircraft, turboelectric aircraft } \\ \eta_{\text {therm }}, \eta_{\text {thermEAC }} & =\text { thermal efficiency of base aircraft, turboelectric aircraft }\end{array}$

\section{Introduction}

$\mathrm{T}$ here is substantial interest in the investigation of improvements to aircraft by the introduction of electrical components into the propulsion system. In the case of a turboelectric aircraft the electrical systems can provide unmatched flexibility in coupling the power generation turbine(s) to the fan propulsors. This flexibility can result in reduced noise, emissions, and fuel burn. However, the greatly expanded electrical system introduces weight and efficiency burdens that oppose these benefits. A break-even analysis is presented here to determine the electrical power system performance level necessary to achieve a net benefit at the aircraft level.

In order to conduct the break-even analysis we will define the key performance parameters, the key functional requirements, and the electrical power system boundary. Then we will formulate range equations for a base aircraft and a turboelectric version of that aircraft. Next we will find the range of possible benefits from a literature survey and calculate the weight and fuel burn costs. Finally, we find the break-even point by setting the ranges of the two aircraft types equal and using the same initial weight, operating empty weight, and payload weight and implicitly solving for the electric drive specific power and efficiency. The resulting parametric curves combined with the functional requirements will be used as input requirements for the electrical power system.

\section{Electric Aircraft and Drive Configurations}

Many configurations of aircraft can be conceived that use some form of electric propulsion. In this analysis, the configurations are categorized by size, aircraft physical configuration, and electrical drive configuration.

Four size categories are considered: regional, single aisle, twin aisle, and very large. Table 1 lists these size classifications along with representative aircraft. The physical configuration of the aircraft refers to the arrangement of the wing and body structure and the configuration of the propulsion system. Both the conventional tube-and-wingand hybrid-wing-body-style airframes are considered. The propulsion system is classified as "concentrated" for four or less propulsors or "distributed" for a larger number of propulsors. Distributed propulsion has the potential to assist the lift, thrust, and drag performance of the aircraft.

A wide electric drive configuration trade space exists. Selected differentiating factors are the power source, the distribution approach, the number of motor-driven propulsors, and the fraction of the total propulsive power that is provided electrically. This analysis will evaluate the performance parameters of a turboelectric system where the system energy is stored as jet fuel. Therefore, the electrical drive considered here will be based on a turbine driving one or more electrical generators, motor driven propulsors, a power distribution system extending from the turbine to the propulsors, and a thermal management system. The power distribution includes power electronics, electrical cables, and protection devices.

The boundary of the electric drive system must be defined prior to determination of key performance parameters. For this paper the boundary will include the electrical machines, the power management and distribution system, and the thermal system specifically related to heat removal in the two prior systems (Fig. 1). By this definition a representative turboelectric system would include generator(s), rectifier(s), distribution wiring, inverter(s), motor(s), and the thermal control for those components.

Table 1. Aircraft Size Classification

\begin{tabular}{ll}
\hline Classification & \multicolumn{1}{c}{$\begin{array}{c}\text { Example } \\
\text { Aircraft }\end{array}$} \\
\hline Regional & Bombardier CRJ700, Embraer E-195 \\
Single Aisle & Boeing 737 and 757, Airbus A320 \\
Twin Aisle & Boeing 777, Airbus A340 \\
Very Large & Boeing 747, Airbus A380 \\
\hline
\end{tabular}




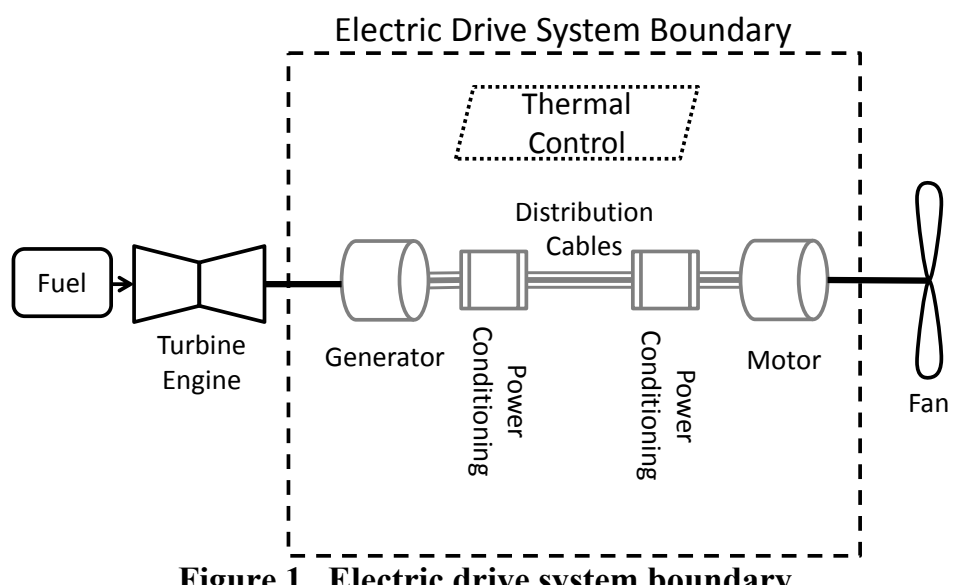

Figure 1. Electric drive system boundary.

\title{
III. Key Performance Parameters (KPPs) and Functional Requirements
}

Key performance parameters and functional requirements are two distinct classes of system requirements. Key performance parameters (KPPs) consist of measurable engineering parameters that can be used to compare system benefits and guide selections for technology application. The KPPs do not include parameters or requirements necessary for internal functionality of the electric drive system. Instead, system functional requirements describe the parameters necessary for operation. The purpose of defining KPPs for the electric drive system is to increase the likelihood of successful technology infusion. ${ }^{1}$ Specific power $\left(S p_{E D}\right)$ and efficiency $\left(\eta_{E D}\right)$ are proposed as the two KPPs of the electric drive system in a turboelectric aircraft. Specific power is the ratio of the rated power to the mass of the system. Efficiency is the ratio of the output power to the input power of the system. These quantities will be used to describe electrical power system performance and establish levels of performance necessary for successful aircraft.

Distinct from the KPPs are the functional requirements of the electric drive system. Two of the crucial functional requirements for a turboelectric aircraft power system are independent speed and power control as well as redundancy and reliability levels.

Independent speed and power control of individual fan propulsors is required in most proposed electric aircraft drive configurations. The basis of this requirement is that it enables configurations that were not previously possible in traditional aircraft, such as fan and turbine speed decoupling, optimal operation throughout the flight regime, yaw control through differential thrust, ${ }^{2}$ the ability to provide high-velocity wing blowing with controlled thrust, and noise reduction strategies.

Redundancy and reliability requirements are not yet well defined for an electric aircraft drive system; however, it is clear that the system must at least meet the safety standards that current aircraft propulsion systems meet. Armstrong et al. summarizes the key requirements and implications: ${ }^{2}$

\begin{abstract}
Fail-safe requirements indicate that no single point failure should yield catastrophic consequences at the aircraft level. The overall weight, volume, and maximum capability levels for airborne power systems are determined by the levels of redundancy and oversizing required to support flight critical and safety critical loads during off-nominal failure scenarios.
\end{abstract}

Therefore, it is assumed in this analysis that turboelectric drive systems must include the components that both allow expanded functionality through independent speed and power control and allow for reasonable reliability through oversizing, redundancy, and protection features.

\section{Relationship Between KPPs and Aircraft Range}

A simplified assessment of the relationship between the electric drive system KPPs and the aircraft range $R_{A C}$ is proposed for top-level aircraft performance comparisons. The basis of the analysis is an expansion of the traditional terms in the Breguet range equation (Eq. (1)) to include the efficiency and weight of the turboelectric drive. As such, it applies for situations where overall efficiency $\eta_{\text {overall }}$, lift-to-drag ratio $L / D$, and flight velocity are constant over the flight. Given these constraints, the range $R_{A C}$ can be found if the intial ( $\left.W_{\text {initial }}\right)$ and final weight $\left(W_{\text {final }}\right)$ of the aircraft 
is known along with the fuel energy per unit mass $h$ and the gravitational constant $g$. Although not true for the entire flight envelope, this description is a reasonable approximation for cruise conditions:

$$
R_{A C}=\frac{h}{g}\left(\frac{L}{D}\right) \eta_{\text {overall }} \ln \left(\frac{W_{\text {initial }}}{W_{\text {final }}}\right)
$$

First, we expand the terms in the overall efficiency to include an electrical efficiency $\left(\eta_{\text {elec }}\right)$ in addition to the thermal and propulsive efficiency typically used and denote the thermal and propulsive efficiency terms of the turboelectric aircraft with an additional EAC subscript:

$$
\eta_{\text {overalleAC }}=\eta_{\text {thermEAC }} \eta_{\text {elec }} \eta_{\text {propEAC }}
$$

Next, we recognize the additional weight of the electrical drive impacts both the initial (Eq. (3)) and final weight (Eq. (4)) of the turboelectric aircraft ( $W_{\text {initialEAC }}$ and $W_{\text {finalEAC }}$, respectively) and expand each to explicitly account for the operating empty weight $\left(W_{O E W}\right)$, payload weight $\left(W_{p a y}\right)$, and fuel weight $\left(W_{\text {fuelEAC }}\right)$.

$$
\begin{gathered}
W_{\text {initialEAC }}=W_{O E W}+W_{\text {pay }}+W_{\text {fuelEAC }}+W_{\text {elec }} \\
W_{\text {finalEAC }}=W_{O E W}+W_{\text {pay }}+W_{\text {elec }}
\end{gathered}
$$

The turboelectric range equation is now stated (Eq. (5)), recognizing that the turboelectric system can result in changes in $L / D$, thermal efficiency, propulsive efficiency, initial weight, and final weight of the aircraft.

$$
R_{E A C}=\frac{h}{g}\left(\frac{L}{D}\right)_{E A C} \eta_{\text {overalleAC }} \ln \left(\frac{W_{\text {initialEAC }}}{W_{\text {finalEAC }}}\right)
$$

In subsequent sections it will be shown that the overall efficiency is impacted by the electrical drive efficiency $\mathrm{KPP}$, and the ratio of the initial-to-final aircraft weight is impacted by both the electrical drive efficiency and specific power KPPs.

\section{Benefits from Turboelectric Aircraft Propulsion}

In this section, we describe three proposed system benefits of turboelectric aircraft propulsion and summarize the potential fuel savings described in previous literature. Higher propulsive efficiency due to increased bypass ratio (BPR), higher propulsive efficiency due to boundary layer ingestion, and lift to drag ratio improvements have been frequently cited as enabled by turboelectric propulsion. Although also achieved using alternate mechanical solutions, the introduction of electric coupling between the fan and turbine offers unmatched capability and design flexibility to achieve these increased aircraft system efficiencies.

Introduction of an electric drive system between the turbine and fan, allowing decoupling of their speeds and inletto-outlet area ratios. With this approach, high BPR can be achieved since any number and size of fans can be driven from a single turbine. Increasing BPR results in improved propulsive efficiency. Also, the speed ratio between the turbine and the fan can be arbitrarily set and varied during operation, thereby removing a key constraint. As a result, the fan pressure ratio and the turbine-to-compressor speed ratios can be optimized independently. Studies with a hybrid wing-body (HWB) distributed propulsion system indicate that the distributed propulsion system may optimize near a fan pressure ratio of 1.3 with resulting fuel savings around $4 \%-8 \%{ }^{3,4}$ It is likely that thrust-specific fuel consumption improvements will be somewhat less than propulsive efficiency improvements because of additional drag from larger fan duct areas, however this varies by specific implementation.

Boundary layer ingestion (BLI) increases propulsive efficiency by ingesting lower velocity flow near the airframe into the propulsors, reenergizing the wake and thereby reducing drag. BLI can be implemented on both conventional tube and wing and HWB aircraft. The propulsor is mounted such that the slow-moving flow near the aircraft is ingested, reenergized, and exhausted where the aircraft wake would have been. Plas et al. provided a review of many 
of the early estimations of fuselage BLI benefits, ${ }^{5}$ which ranged from $0 \%-16 \%$; however, further refinement through the years has resulted in estimations between 3\% and 7\%. Uranga et al. at the Massachusettes Institute of Technology predicted the propulsive efficiency benefits of fuselage BLI on tube-and-wing-style aircraft between $5 \%$ and $7 \%$ and verified them using reduced-scale wind tunnel testing for the D8 aircraft concept ${ }^{6}$. In a HWB configuration the propulsors can be positioned for BLI on the top of the airframe, thereby reducing overall drag. A number of recent studies have examined the use of single-fan and multi-fan turbine engines embedded in the upper surface of an HWB aircraft. The predicted fuel burn reductions due to BLI in both configurations have been in the $3 \%-8 \%$ range compared to a pylon-mounted engine of equal technology level., ${ }^{4,7}$

Distributed propulsion is expected to improve both lift and $L / D$ through wing flow circulation control. The propulsors can be distributed above, below, or imbedded in the tradition tube-and-wing configuration. Likewise hybrid wing-body configurations can employ fans distributed across the upper surface or imbedded. Improvements in $L / D$ may result in smaller wing area and reduced drag and weight. The benefits of lift augmentation can be taken in reduced wing area for a given load capacity or shorter takeoff distances. Reduction in wing area reduces wing weight, lowers drag, and thereby imparts fuel savings. Alternatively, the improved lift could be focused on increased climb rate and reduced takeoff distance in order to decrease the noise foot print around the airfield. One recent study by Wick et al. ${ }^{8}$ showed that transonic efficiency can be improved by as much as $8 \%$ for a transport-size aircraft. Stoll et al. ${ }^{9}$ evaluated the benefits of flow circulation control strategies using distributed propulsion on small aircraft and found that wing area could be reduced substantially. There are ongoing efforts to demonstrate the distributed propulsion benefits in small aircraft.

A summary of the ranges of benefits from the above paragraphs are presented in Table 2, including the improved propulsive efficiency due to increased bypass ratio (BPR), and boundary layer ingestion (BLI), and the improved lift-to drag-ratio $(L / D)$ that can be expected for a large transport aircraft. Minimum, median and maximum benefits are listed.

Table 2. Range of Benefits

\begin{tabular}{cccc}
\hline & \multicolumn{2}{c}{ Propulsive } & \\
& $\begin{array}{c}\text { BPR, } \\
\text { percent }\end{array}$ & $\begin{array}{c}\text { BLI, } \\
\text { percent }\end{array}$ & $\begin{array}{c}\text { L/D, } \\
\text { percent }\end{array}$ \\
\hline Minimum & 4 & 3 & 0 \\
Median & 6 & 5.5 & 4 \\
Maximum & 8 & 8 & 8 \\
\hline
\end{tabular}

\section{Costs of Electric Drive}

The previous section enumerated top-level benefits expected from turboelectric propulsion. Further description is also required of the system penalties before comparisons can be made. We now define power terms at different stages of the system. The propulsive power $P_{\text {prop }}$ is the output power of the system, electrical power $P_{\text {elec }}$ is the input power to the electrical drive system, and fuel power $P_{\text {fuel }}$ is the input power to the turbine. Figure 2 illustrates the association between the propulsive subsystems, powers and efficiencies.

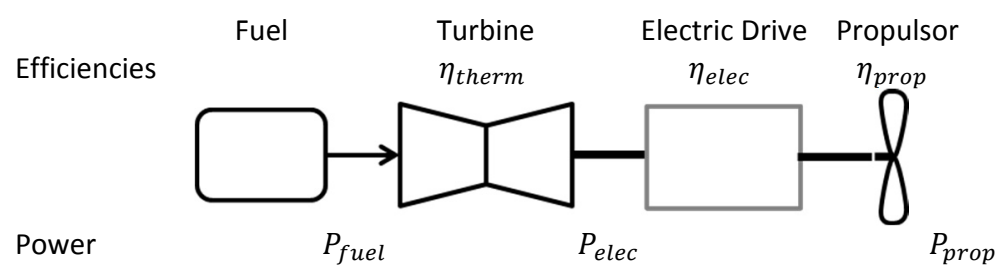

Figure 2. Propulsion power and efficiency terms.

The power relationships are seen in Eqs. (6) and (7):

$$
\begin{gathered}
P_{\text {prop }}=P_{\text {elec }} \eta_{\text {elec }} \eta_{\text {prop }} \\
P_{\text {elec }}=P_{\text {fuel }} \eta_{\text {therm }}
\end{gathered}
$$




\section{A. Electric Drive Specific Power Impact}

The specific power is defined as a key performance parameter because it has a direct impact on electric drive weight. It is a function of the electric drive specific power, initial aircraft weight, propulsive efficiency, and electrical efficiency. The electrical drive system must be sized for the maximum electrical power during the mission, which is occurs during takeoff. First, the thrust at the beginning of the cruise phase is found using the aircraft force balance:

$$
T=\frac{W_{\text {initialEAC }}}{(L / D)_{E A C}}
$$

The following expression for the beginning of cruise electrical power is developed by recalling that the propulsive power is equal to the product of thrust and velocity, and recalling that the electrical power is equal to the propulsive power divided by the product of propulsive efficiency and electrical efficiency:

$$
P_{\text {eleccruise }}=\frac{W_{\text {initialEAC }} v_{\text {cruise }}}{(L / D)_{E A C} \eta_{\text {elec }} \eta_{\text {propEAC }}}
$$

The factor $\alpha$ is defined as the ratio of the takeoff power to the cruise power. For an initial approximation, the ratio of static to cruise thrust and rotation velocity to cruise velocity is used:

$$
\alpha=\left(\frac{T_{\text {takeoff }}}{T_{\text {cruise }}}\right)\left(\frac{v_{\text {takeoff }}}{v_{\text {cruise }}}\right)
$$

The takeoff power is estimated from the beginning of cruise power by including $\alpha$ in Eq. (8):

$$
P_{\text {electakeoff }}=\frac{W_{\text {initialEAC }} v_{\text {cruise }} \alpha}{(L / D)_{E A C} \eta_{\text {elec }} \eta_{\text {propEAC }}}
$$

Finally, we find the drive weight from the ratio of the electrical power and the specific power KPP:

$$
W_{\text {elec }}=\frac{W_{\text {initialEAC }} v_{\text {cruise }} \alpha / S p_{E D}}{(L / D)_{E A C} \eta_{\text {elec }} \eta_{\text {propEAC }}}
$$

\section{B. Electric Drive Efficiency Impact}

The goal of introducing the electric drive is to increase the overall aircraft efficiency, which is the product of the thermal, electrical, and propulsive efficiencies. However, in order to isolate the impact of electrical efficiency, we hold the thermal and propulsive efficiencies unchanged from those of the base aircraft for calculations in this section. The electric drive impacts aircraft fuel burn directly by reducing the efficiency of the system, and indirectly by increasing the amount of fuel that needs to be carried (and therefore the initial weight of the aircraft). The direct efficiency impact is accounted for in the turboelectric aircraft range equation (Eq. (5)) by the electrical efficiency.

The weight penalty of the additional fuel resulting from the electrical drive losses is estimated by introducing the additional electrical inefficiency term into the overall efficiency, then holding all parameters on the base aircraft fixed. Using these assumptions we can find the change in fuel weight from the difference of original fuel weight divided by the electrical efficiency, less the original fuel weight:

$$
\Delta W_{\text {fuel }}=W_{\text {fuel }}\left(\frac{1}{\eta_{\text {elec }}}-1\right)
$$


This equation can also be written in terms of the base aircraft fuel fraction $\zeta_{A C}$ :

$$
\Delta W_{\text {fuel }}=\zeta_{A C} W_{\text {initial }}\left(\frac{1}{\eta_{\text {elec }}}-1\right)
$$

\section{Combined Specific Power and Efficiency Weight and Fuel Burn Cost}

The aircraft-level burden associated with the electrical system can be estimated as the combination of the direct cost of lost efficiency and the additional weight penalty. By combining these terms and normalizing by the initial aircraft weight, the turboelectric drive weight is developed as a function of specific power and efficiency of the drive:

$$
\frac{W_{\text {elec }}+\Delta W_{\text {fuel }}}{W_{\text {initial }}}=\frac{v_{\text {cruise }} \alpha / S p_{E D}}{(L / D)_{\text {EAC }} \eta_{\text {elec }} \eta_{\text {propEAC }}}+\zeta_{A C}\left(\frac{1}{\eta_{\text {elec }}}-1\right)
$$

Using some representative numbers for a large transport aircraft $\left(v_{\text {cruise }}=850 \mathrm{~km} / \mathrm{h}, \alpha=1.6,(L / D)_{E A C}=17\right.$, $\eta_{\text {prop }}=0.6, \zeta_{E A C}=0.27$ ), we can now plot this relationship. Figure 3 illustrates the direct weight impact, the fuel weight impact, and the combined impact for a $95 \%$-efficient system. Note that the efficiency sets the minimum limit of weight or fuel burn penalty irrespective of the drive specific power. Figure 4 illustrates the combined weight penalty for three different efficiency levels.

The increased fuel burn is estimated as the sum of the drive efficiency cost and the normalized weight change. The basic assumption is that a $1 \%$ weight gain on the aircraft results in a $1 \%$ increase in required fuel as justified by the aircraft force balance given in Eq. (8). A $1 \%$ increase in weight results in a $1 \%$ increase in thrust required. Holding the aircraft parameters fixed also results in a $1 \%$ increase in fuel burn.

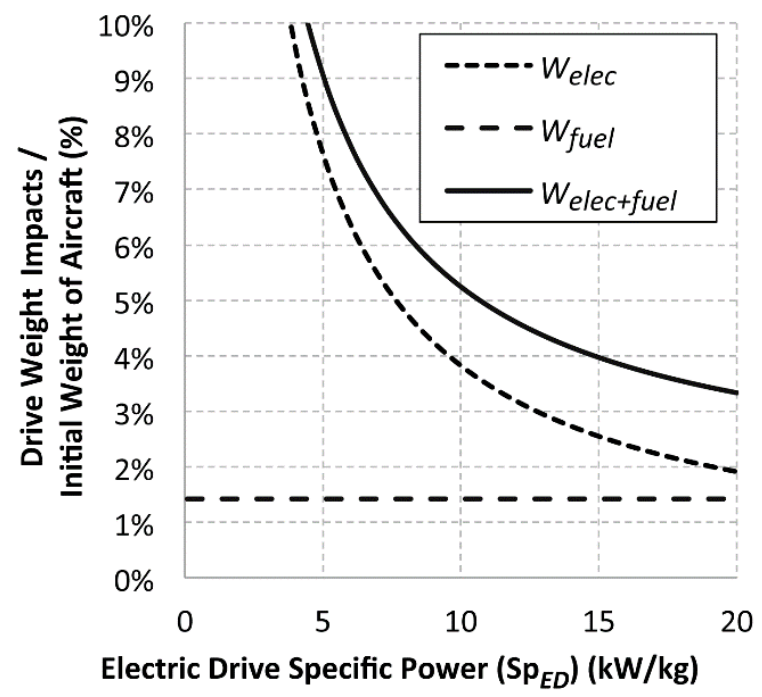

Figure 3. Normalized weights of drive, fuel impact of inefficiency, and combined costs for $95 \%$ efficient drive.

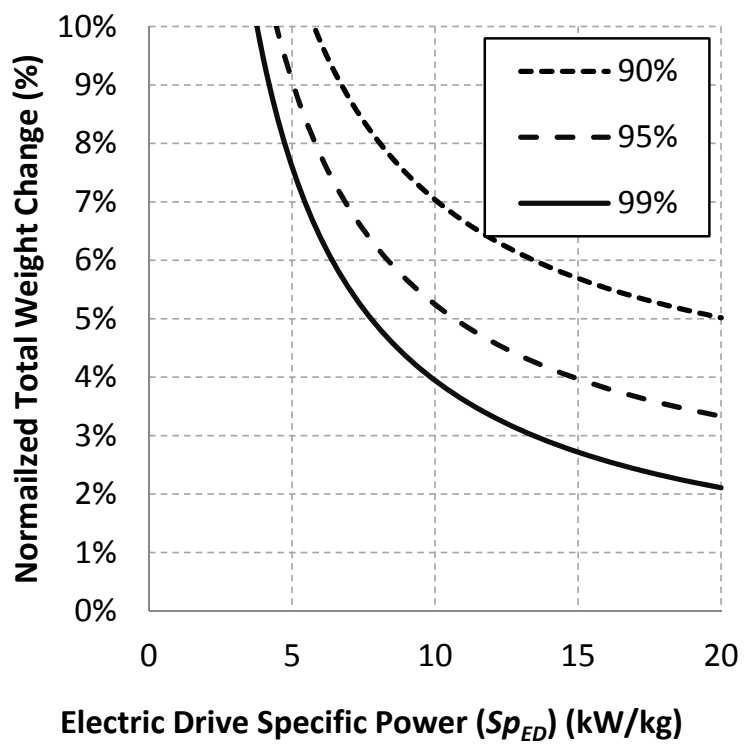

Figure 4. Normalized Total Weight Change for Select Drive Efficiencies. 
Figure 5 is a plot of the increase in fuel burn as a function of specific power for select drive efficiencies. Observe that below a specific power of approximately $3 \mathrm{~kW} / \mathrm{kg}$ there is a very strong relationship between specific power and fuel burn change. Conversely, above a specific power of $10 \mathrm{~kW} / \mathrm{kg}$ the increasing specific power has a small impact on fuel burn. Another interesting result is that even as specific power goes to infinity ( $W_{\text {elec }}$ is zero), the increase in fuel burn is noticeably higher than that of the efficiency loss alone, because of the impact of the increased weight associated with carrying more fuel.

\section{KPP Break-Even Analysis}

The break-even analysis determines the electric drive specific power and efficiency where the costs of adding the drive exactly equal the benefits. This is a first-order analysis where the aircraft systems parameters are fixed to focus the evaluation on the aerodynamic and propulsive changes due to the introduction of the turboelectric drive. Base aircraft and turboelectric aircraft performance parameters are constant in this analysis. The range and payload weight are held constant as the major mission parameters, the initial weight is fixed because it largely influences the component sizing, and the operating empty weight is also held constant.

First, the range expressions of the base aircraft and the turboelectric aircraft are equated:

$$
\frac{h}{g}\left(\frac{L}{D}\right) \eta_{\text {overall }} \ln \left(\frac{W_{\text {initial }}}{W_{\text {final }}}\right)=\frac{h}{g}\left(\frac{L}{D}\right)_{\text {EAC }} \eta_{\text {overallEAC }} \ln \left(\frac{W_{\text {initialEAC }}}{W_{\text {finalEAC }}}\right)
$$

Then the common terms are canceled and the efficiency terms expanded:

$$
\left(\frac{L}{D}\right) \eta_{\text {therm }} \cdot \eta_{\text {prop }} \ln \left(\frac{W_{\text {initial }}}{W_{\text {final }}}\right)=\left(\frac{L}{D}\right)_{E A C} \eta_{\text {thermEAC }} \eta_{\text {elec }} \eta_{\text {propEAC }} \ln \left(\frac{W_{\text {initialEAC }}}{W_{\text {finalEAC }}}\right)
$$

Next, the terms are arranged so the benefits are on left and costs are on the right with expanded weight terms

$$
\frac{\left(\frac{L}{D}\right)}{\left(\frac{L}{D}\right)_{E A C}}\left(\frac{\eta_{\text {therm }}}{\eta_{\text {thermEAC }}}\right)\left(\frac{\eta_{\text {prop }}}{\eta_{\text {propEAC }}}\right)=\eta_{\text {elec }} \frac{\ln \left(\frac{W_{\text {initial }}}{W_{\text {OEW }}+W_{\text {pay }}+W_{\text {elec }}}\right)}{\ln \left(\frac{W_{\text {initial }}}{W_{\text {OEW }}+W_{\text {pay }}}\right)}
$$

Finally, the electrical drive weight as function of specific power, and the aircraft parameters (Eq. (12)) is included:

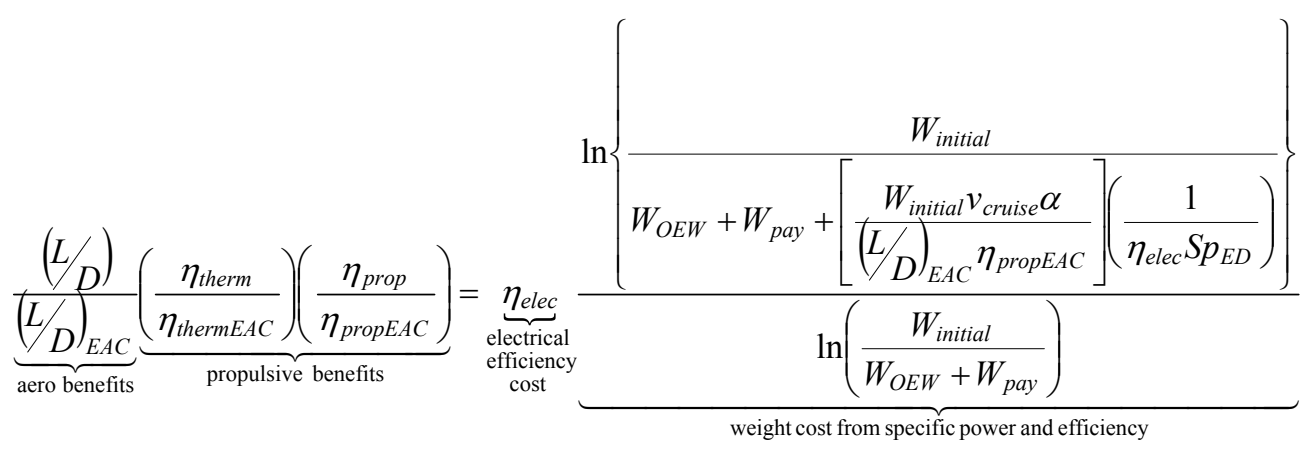


Now we consider the form of Eq. (19). The benefits on the left are in terms of performance comparison ratios between the base and the turboelectric aircraft. First, the aerodynamic changes are captured in the ratio of lift-to-drag performance, followed by the thermal and propulsive efficiency changes. The product of those ratios is the maximum total benefit, with a reduction in fuel burn indicted by a product less than unity. The right side has two main elements: the direct impact of electrical efficiency, and the weight impact related to the electrical drive specific power and efficiency.

Break-even specific power and efficiency lines are now compared for the base aircraft and turboelectric aircraft using the minimum, median, and maximum expected BPR, BLI and $L / D$ benefits. No change in thermal efficiency between the base and turboelectric aircraft is assumed. Table 3 lists the $L / D$, propulsive efficiency, and benefit product for each case. The benefit product is the product of $L / D$, the thermal ratio, and the propulsive ratio between the base aircraft and the turboelectric aircraft. Both aircraft are assumed to

Table 3. KPP Break-Even Cases

\begin{tabular}{cccc}
\hline & $\boldsymbol{L} / \boldsymbol{D}$ & $\begin{array}{c}\eta_{\text {prop }}, \\
\eta_{\text {propEAC }}\end{array}$ & $\begin{array}{c}\text { Benefit } \\
\text { Product }\end{array}$ \\
\hline Base Aircraft & 17 & 0.6 & \\
Min. Turboelectric & 17 & 0.64 & 0.93 \\
Med. Turboelectric & 17.7 & 0.67 & 0.86 \\
Max. Turboelectric & 18.4 & 0.70 & 0.79 \\
\hline
\end{tabular}
have a velocity of $850 \mathrm{~km} / \mathrm{h}$ (Mach 0.8), and the base aircraft will have a fuel fraction of 0.27 .

Figure 6 shows the specific power and efficiency relationship using the above aircraft parameters and the medianlevel benefit estimates. With these assumptions, the minimum required drive specific power must be approximately $9 \mathrm{~kW} / \mathrm{kg}$ if the system is $100 \%$ efficient and the minimum required efficiency is $92 \%$ at a specific power of $20 \mathrm{~kW} / \mathrm{kg}$. Along the break-even line, the fuel weight reduction is equal to the additional electric drive weight. The fuel burn along this line is less than that of the base aircraft. If the system has KPP parameters are in the region above the curve, the overall system will close with a reduction in the combined fuel and drive weight, which can be taken as payload or some alternate benefit. Figure 7 is a plot of the break-even curves for the three levels of benefit assumptions. The minimum benefit case does not close below $20 \mathrm{~kW} / \mathrm{kg}$. Not surprisingly, if the benefits are large, the KPPs of the power system do not need to be as aggressive. If the benefits are small, the KPP requirements become substantially more difficult. For example, the minimum required specific power is increased from approximately $6 \mathrm{~kW} / \mathrm{kg}$ in the maximum benefit case to approximately $9 \mathrm{~kW} / \mathrm{kg}$ the median benefits case.

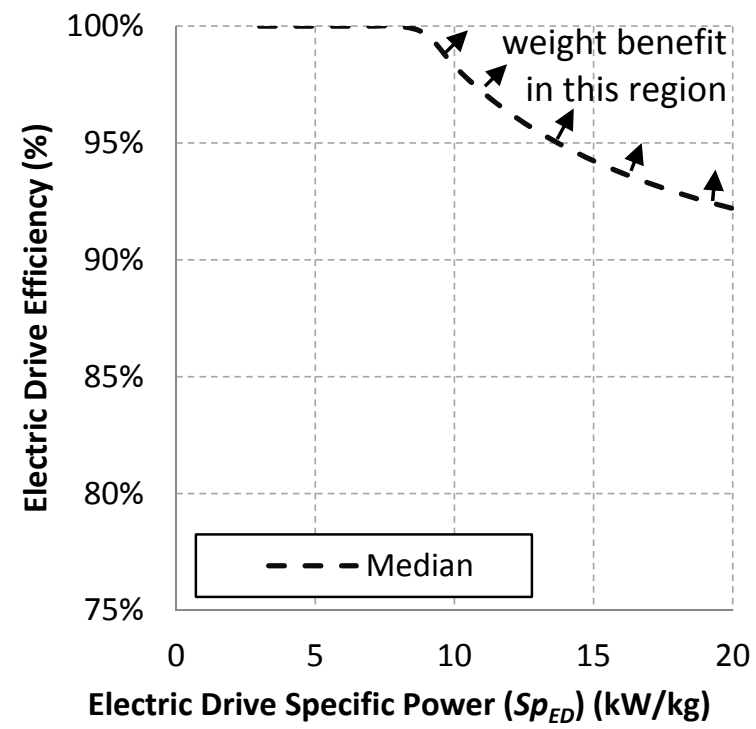

Figure 6. KPP break-even with net benefit region.

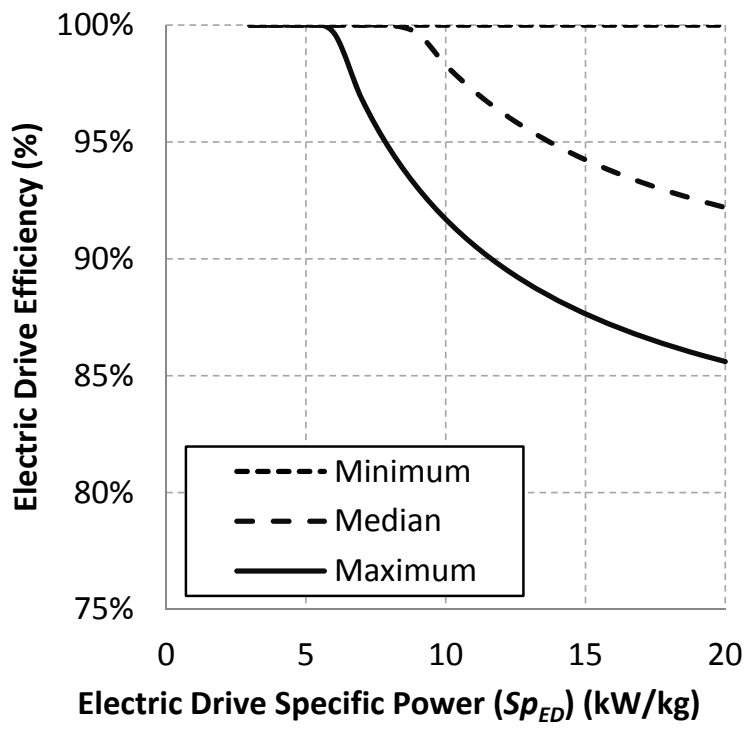

Figure 7. KPP break-even curves for a range of benefits.

\section{Conclusions}

Specific power and efficiency are proposed as two key performance parameters for the electric drive system of a turboelectric aircraft. The boundary of the system is defined between the output shaft of the turbine to the input shaft of the propulsor and includes the electrical machines, power distribution, any other power components related to 
propulsion, and any thermal systems associated with the power system. The Breguet range equation was developed for the turboelectric aircraft and then combined with the Breguet range equation for the base aircraft in order to develop an equation that compares the benefits with the costs of a turboelectric system. The costs were associated with the proposed KPPs. Analysis of the costs leads to the conclusion that below a specific power of approximately $5 \mathrm{~kW} / \mathrm{kg}$, the specific power is the dominant cost, whereas above that level the efficiency becomes dominant. Additionally it is noted that the fuel burn cost can never be less than the inefficiency of the electric drive system. Finally the KPP break-even weight curves are found that correspond to the minimum, median, and maximum estimated benefits resulting from the implementation of the turboelectric system. The region of power system performance that will result in a net weight benefit is shown. Further work will need to be done to define the net fuel burn benefit region. Additionally it is shown that the greater the combined aerodynamic and propulsive benefits are, the lower the specific power and efficiency of the turboelectric drive can be for the break-even case.

\section{References}

${ }^{1}$ NASA, "NASA Research and Technology Program and Project Management Requirements," NPR 7120.8, 2013.

${ }^{2}$ Armstrong, Michael, Ross, Christine, Phillips, Danny, and Blackwelder, Mark, "Stability, Transient Response, Control, and Safety of a High-Power Electric Grid for Turboelectric Propulsion of Aircraft," NASA/CR 2013-217865, 2013.

${ }^{3}$ Felder, James L., Kim, Hyun Dae, and Brown, Gerald V., "Turboelectric Distributed Propulsion Engine Cycle Analysis for Hybrid-Wing-Body Aircraft," AIAA 2009-1132, Reston, VA, 2009.

${ }^{4}$ Brown, Gerald V., "Weights and Efficiencies of Electric Components of a Turboelectric Aircraft Propulsion System," AIAA 2011-225, Reston, VA, 2011.

${ }^{5}$ Plas, A. P., et al.: "Performance of a Boundary Layer Ingesting (BLI) Propulsion System," AIAA 2007-450, Reston, VA, 2007.

${ }^{6}$ Uranga, Alejandra, et al., "Preliminary Experimental Assessment of the Boundary Layer Ingestion Benefit for the D8 Aircraft." AIAA 2014-0906, Reston, VA, 2014.

${ }^{7}$ Felder, James L., Brown, Gerald V., Kim, Hyun Dae, and Chu, Julio, "Turboelectric Distributed Propulsion in a Hybrid Wing Body Aircraft," 20th International Society for Airbreathing Engines, ISABE-2011-1340, Gothenburg, Sweden, 2011.

${ }^{8}$ Wick, Andrew T., Hooker, John R., Hardin, Christopher J., and Zeune, Cale H., "Integrated Aerodynamic Benefits of Distributed Propulsion," 53 ${ }^{\text {rd }}$ AIAA Aerospace Science Meeting, AIAA SciTech, Kissimmee, FL, 2015.

${ }^{9}$ Stoll, Alex M., Bevirty, JoeBen, Moore, Mark D., Fredericks, William J., Borer, Nicholas K., "Drag Reduction Through Distributed Electric," Aviation Technology, Integration, and Operations Conference, AIAA, Atlanta, GA, 2014.

\section{Acknowledgments}

This work is sponsored by the NASA Advanced Air Transportation Technologies project. The methods used in this paper build on an analytical approach developed by Gerald Brown for preliminary analysis of weights of electrical drive systems. 